\title{
Factors Influencing of SSCM Performance of the Indian Insurance Industry: An ISM Approach
}

\author{
Puspalata Mahapatra, KIIT University (Deemed), Odisha, India \\ Sushanta Tripathy, KIIT University (Deemed), Odisha, India \\ (iD) https://orcid.org/0000-0003-2470-4080
}

Surya Kanta Panda, Kunja Bihari College, Barang, India

\begin{abstract}
In today's economy, service supply chain management draws surprisingly more attention, and the insurance sector is one among them. Here, the study is an attempt to overcome the challenges that impacts the effectiveness, efficiency, and success of SSCM of the Indian insurance industry. To show the hierarchical interrelationship among the selected significant factors of the insurance industry, an integrated comprehensive framework has been developed, displayed, and explained through an interpretive structural modelling (ISM) technique. Beneath the study, various classification of influential factors have been carried out like autonomous, linkage, dependencies, and driving force. Finally, this study developed a hierarchical structure of selected prominent factors responsible for the success of SSCM of the Indian insurance industry by using ISM technique. The findings so drawn from the study can be used by the Indian insurers and foreign insurers.
\end{abstract}

\section{KEYWORDS}

Autonomous, ISM, SSCM, Supply Chain

\section{INTRODUCTION}

Service supply chain simply refers to supply of services to any organization, may be manufacturing, service or public sector, and the delivery of these services to customers (Baltacioglu et al., 2007). Service supply chain manage and plan the whole activities along with the chain of services that is delivered from the service providers to the end users. The low material flow visibility level of service supply chain restricts the utilization of existing product based supply chain approaches directly (Saliha Karadayi,2014). It is also a network of suppliers, service providers, consumers and other supporting units that perform the functions of transaction of resources required to produce the service. Although now a days SSC became surprisingly important and treated as main driving force for the growth of economy, but unfortunately there is inadequate integrated comprehensive framework of it, specially in the field of insurance sector. However, it is noticed that the notable contribution of service sector (more than 50\%) to GDP is more and ahead of manufacturing sector of India (Majumdar et al., 2015) and it highlights the necessity of competently managed service 
supply chain management, but still relatively little literature is obtainable as compared to other Industries. According to Bentalha \& Hmioui (2019) supply chain management (SCM) was born and developed first in an industrial context and in the field of services, little research has addressed the issue of the company's SCM. With the globalization of markets, combined with the advancement of information technology and ready availability of manufacturing technology, the supply chain management process has spread globally for many businesses (Das et al., 2013). Hendrick \& Singhal (2005) empirically established that supply chain disruptions have a significant negative impact on shareholder value and on operating performance of the firm. Many of the firms recognize that an assertive SCM could lead to an important competitive advantage in the business world and it also enhance the firm's performance (Catia et al.,2020). Effective supply chain management (SCM) has become a potentially valuable way of securing competitive advantage and improving organizational performance since competition is no longer between organizations, but among supplychains (Lia, 2004)Though SCM is becoming more emerging area for researchers, academics and practitioners, still conducting research on manufacturing or traditional supply chain rather than service supply chain management prospective because of nature of industry's complexity. So, research on service supply chain is immature and there is still some deficiency to study on service supply chain management. (Somabutr et al.,2020). In India,it is also experienced that there is a noticeable less understanding about the concept of Service Supply Chain, Development of SSCM model and Identification of the influential factors for the successful application of SSCM (Zailani \& Kumar 2011). According to Zhang \& Chen (2015), the main challenges which generally affects the efficiency and usefulness of SSC management is the inadequate SSC management framework. So to bridge the existing gap, here the study tries to identify the influential enablers and to develop an Interpretive Structural Model (ISM) in order to gain better insight into the current body of knowledge for the successful performance of SSCM of Indian insurance industry.The purpose of the study is to point out the influential factors accountable for the effective performance of of SCM of Indian insurance industry and to establish the contextual relationship among them through the development of ISM approach.This article shows that the performance of SSCM of Indian insurance sector has some drivers which could be different to different countries according to the risk perception of customers, their attitude, culture, distribution channel and CRM of insurers. This paper provides a ISM approach based framework for analyzing intangible factors accountable for the thriving performance of SSCM of Indian insurers. This analysis yields a transparent road map based on the contextual relationship among Depended, their driving powers, Linkage and Autonomous factors of the study.

The proposed paper has been structured as follows: Section-I gives a brief description about SSC with respect to Indian insurance industry, Section-II summarizes, related work and the conclusions which are drawn from the past works about the key influential factors affecting the success of SSC and ISM, and Section III deals with the conceptual discussion about the 12 Key enablers that are responsible for the successful implementation of SSC in Indian Insurance industry . Section-IV presents the proposed ISM methodology, which contains the structure of interrelationship among the identified influential factors followed by Section- $\mathrm{V}$, which illustrate results and discussions and Section-VI discusses about the conclusions, which are drawn based on the ISM in SSC of Indian Insurance Industry.

\section{RELATED WORK}

When literature Review is accomplished under the study, it was being observed that comparatively little works have been carried out specially in insurance industry by applying ISM methodology context to explore the success, driving and interdependent factors responsible for the successful performance of Service supply chain management of Indian insurance industry. Some of the related works cited during the study. Here the study focused on 82 articles which are more compatible with the topic and 
from these literature author classified them on the basis of key success factors of SSCM and ISM methodology and around 32 themes arose, as explained in the following subsections.

Kumar \& Sridharan (2019) revealed that supply chain is a challenging research area in supply chain management. \& his review on SSCM will help other researchers to identify the potential areas for research on sustainable SCM. Catia \& Paulo (2005) recognized that assertive SCM could lead to competitive advantages in the business world \& through the study they tried to highlight which SCM practice have a superior and positive effect on the performance of the organization. Artus Krohn, developed a system dynamic model for forecasting, prioritizing and distributing critical supplies during relief operation in case of hurricane event. Through the developed system study tries to establish the people's decision with respect to determine the time of evacuation and reveals which routes cause more delays during distribution of relief supplies. Mohseni et al., (2018) tried to identify and analyze influential practices for implementing sustainable supply chain management which will the top management to focus on them to improve the performance and to win over the global competitors. Bhusan (2017) studied on humanitarian supply chain and attempted to develop a system dynamic model in order capture inter linkage within the system \& finally tried to prove how HSC enhance the overall performance of the system. According to Iqbal \& Mahamad (2019) supply chain risks can be categorize as supply,operation, demand risks and other risks. Here study provides a detailed review of supply chain risks and risk management strategies specially related with supply chain of ornamental fish. Krohn et al.,(2017) through their study attempted to streamline Automotive component industry supply chain management with the help of cloud computing and same time tried to highlight the effect of using cloud computing along with CRM strategies, better service delivery for optimizing the resources.

Majumdar \& Tripathy (2018) indicated that the service sector is considered to be the tertiary sector of Indian economy and services provided are not really physical in nature but consists of hospitality, banking and insurance services, retail, logistics, education, health care, community services, real estate, broadcasting \& tourism etc. Farokhian \& Toorga (2011) described about the CSF of Iran insurance industry, and suggested that Customer satisfactions which includes product customization and Service Quality which depends upon CRM \& Policy terms are the main factors for the success of the Industry.PEFINDO Rating Criteria \& Methodology (2019) highlighted that distribution channel,risk assessment, market position, penetration of branch, asset quality are operating performance are the key success factors of Insurance Industry. Mohesen Miri (2019) focused that Insurance Companies for their growth and long run survival should pay more attention to their Supply chain, service quality, customer satisfactions and pricing of the product.Montserrat, Scheike and Nielse (2012) have attempted to discuss that a satisfied customer stays true to the company and enhance the brand for the company's image and its products, and they are less sensitive to price also. So to satisfy the customer the Company should focus on CRM, Service Quality and Distribution Channel. Saxena (2019) commented that now a days most disheartening fact is lack of awareness about insurance in rural and semi urban areas and in urban areas it is not up to mark also.According to CII, (2018) the Indian insurers are advised to address two key areas to improve the conversion rate of policy holders are increased awareness, \& simplified product terms \& condition. Schramm (2008) proposed that the design,innovation,implementation of new and altered products create new value to customers and financial return to organization.Venketash Ganapathi (2019) pointed out that the Indian insurers should develop viable and cost effective distribution channel, exclusive rural centric products and sale low ticket products to the rural people to develop the insurance market. Zainuddin Zakaria et al. (2016) indicated the relationship between awareness and purchase of life insurance products. According to him,Insurance is a feelings of uncertain (risk) and it is influenced by precautionary motive against personal risk (life \& health) and disability risk. Majumdar \& Tripathy (2018) discussed that the application of SCM in educational industry which unlock its application in different sectors of service industry can be verified through ISM technique. SSCM can establish its effective and feasible relationship among internal and external factors of service industry.Richard. H.Watson (1978) pointed 
out that ISM is an systematic \& comprehensive computer based technique, which helps the people $\&$ organization for integrating group judgement of the complex problem through Structural Model. Habib Md \& Mammun (2011) discussed that SCM is needed in an organization for many reasons like to provide quality service to customers, increasing the amount of profit,for providing quality customer service and tackling competitive pressure. Shahin (2014) highlighted that though SSCM is complicated as compared to SCM of manufacturing industry, it provides a substantial advantages such as flexibility in delivery, dynamic scheduling and process orientation. Baltaciogllu et al. (2007) clearly indicated that the proper SSCM practice is an effective tool to face the challenge like to gain the competitive advantages and to survive in the long run. The proper understanding of SCM practice will put the remarkable impact on the performance and financial efficiency of the Service Industry. Luthra \& Haleem (2015) highlighted the fact that work as hurdles in implementing sustainable supply chain management in Automobile sector. Political instability and unawareness among society are found most important driver hurdles for implementing SSC \& global and customer pressure forced to implement SSCM to improve their environmental performance over economic performance. In this study the researchers tried to analyse the enablers for implementing SSCM into Indian industries and they used ISM technique for identifying these enablers. Rameswar Dubey et al. (2017) identified antecedents \& drivers for applying the SSCM and argued for the adoption of alternative method to address the questions about SSCM drivers and finally used TSIM to extrapolate SSCM drivers and their relationship. Keradayi Saliha et al. (2014) did their thorough study of past literature on SSC and suggested about the frame work to deal with, its process, methodology and model specific to SSC. Gunasekoran (2004) highlighted that SCM has been a vital element of competitive strategy to intensify the organizational profitability and productivity. Mohmood \& Mengeke et al. (2017) analyzed the critical success factors for the attainment of sustainable supply chain management. Through the ISM, the authors discussed the mutual impact of most prominent success factors for the implementation of SSCM.Yusuf \& A.Musa et al. (2014) brought to notice that many companies have shifted their prime focus towards SCM to enhance their sustainable competitive gain and there is an increasing requirement for integrating Eco friendly practice into sustainable supply chain management.

\section{METHODOLOGY}

For the fulfillment of objectives of the study, the prominent influential factors have been identified by using some of the instruments like questionnaire, survey, literature review and expert opinion. First a well structured questionnaire was developed on the basis of past literature followed by a survey conducted among 100 respondent from the state of Odisha, out of which 82 nos. were properly filled up. Here the study also conducted a brainstorming session with 21 experts of Insurance industry including Authority, Executives, Academicians. This session includes prioritizing the selected thirty factors from the given survey questionnaire, they felt the most important factors influential for the successful performance of SSCM of Insurance industry. From the ranks of the selected responses, twelve influential factors were summed and also validated through ranking by expert's brainstorming session. Finally, 12 key factors are selected by the expert's analysis as influential factors for the success of SSCM of Indian Insurance Industry.

\section{FRAMEWORK OF FACTORS INFLUENCING THE SERVICE SUPPLY CHAIN MANAGEMENT (SSCM) OF INSURANCE INDUSTRY OF INDIA (FIGURE 1)}

\subsection{Influential Factors of SSCM of Insurance Industry}

The study has identified and used 12 attributes which are considered as potent to build up the performance of the SSCM of Indian Insurance Industry. 


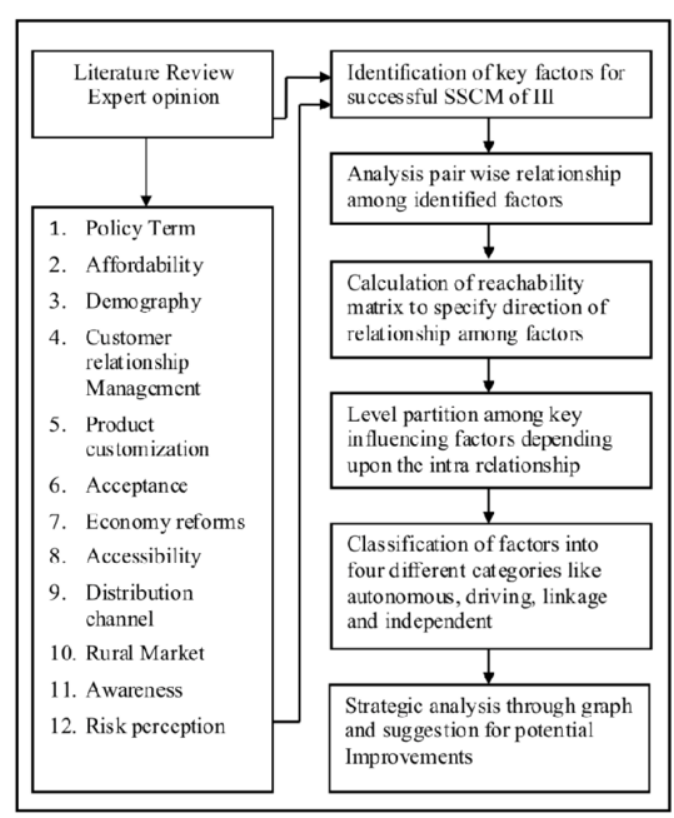

\subsubsection{Demography}

Indian Insurers should consider Customer segment, Demography of Customers, Preferred Language, Mode of Communication \& Financial literacy level of people for selling the product portfolio (CII,2018).Demographic factors of the consumers play a major role in deciding both the purchasing decision of the insurance policy and the preference about a particular insurance company (Y.V.Reddy $\&$ Sweta \& Purnima, 2015). The different socio economic factors like age, gender, location, occupation and the income level play a major and pivotal role in influencing the behavior of the consumer while purchasing the policies and as a result it affects the performance of the SSCM of Indian Insurance Industry.

\subsubsection{Risk Perception}

A Risk perception is a process by which a consumer selects a product with distinct characteristics, which can either, be intrinsic or extrinsic (Onafalujo, Akinwunmi Kunle (2011). The risk-averse attitude is the most influential factor in the insurance participation decision (Li-Hsien, Chien 2009). This indicates that there is significant relationship between demand for the insurance products and risk perception of policy holders of that country. It is observed that the demand for long term insurance products is low due to the low risk perception. Different people have different misconception about risk due to which they may wrong choice of insurance or sometimes they avoid buying of insurance (Cristian Buzatu, 2013) 


\subsubsection{Economy Reforms}

Indian Insurance Industry is a highly regulated industry, which constantly reviews to adjust its product innovations to ensure the regulatory compliance of the Authority. The regulations like the economic reforms and the new guidelines framed by the regulatory authorities like IRDA and Govt. of India impact every aspect of the insurance companies with respect to product design, product development, product filling rate or price approval, tax treatment like GST and giving the disclosures.

\subsubsection{Production Customization}

While designing the products and going for product customization,insurers should consider customer segments, demographics, preferred languages, mode of communication, and their paying capacity which will suit their needs and preference (CII,2018). Customization of the products is one of the strategies of the insurers to retain the existing customers and to attract the new customers, which will help in the successful performance of the supply chain management of the insurance companies. Now a day the customers are not only purchasing the traditional policies rather they are buying products and services based on their exact and true needs. So widening of the product basket and making the product customize has the significant impact on the success of the industry. Now the Indian Insurers shifted from mass market to personalized products, which are innovative and immediately available to meet the unique needs of the customers.

\subsubsection{Policy Terms}

There is a significant relationship between the policy documents and the purchasing decision and it is evident from the study that simplified policy documents and proposal form plays a major contributing factor for the acceptance of the insurance policy by the customers. Understanding of policy features, terms and benefits, followed by complex and lengthy processes, are the key areas that customers in Indian market are struggling with.So the policy terms used in the Insurance should be simplified to be understandable by customer with objectives to increase the revenue (Confederation of Indian Industry,2018) So the documentation process of the Indian Insurance companies should not be complicated but simple enough which irrespective of the persons irrespective of educational level and location can easily fill. Simple and effective documentation will motivate particularly the rural customers to purchase the insurance products form the Insurance companies.

\subsubsection{Rural Market}

Now a days rural market should be the latest mantra of Insurance companies. Indian rural market is a combination of no distribution system, lack of technology,poor reach of products and lower level of awarenes (Ashfaqas Ahmad, 2014). As the rural Market is rural consumer centric and the transactions taking place in the rural market are very limited in terms of Products and services due to unstable income level, Poor health literacy rate which over powers their buying capacity. The rural customers are the risk avoiders for which the insurance companies cannot apply similar marketing methodology as they apply in urban areas.

\subsubsection{CRM}

Sridevi (2012) identifies that firm's image service quality and CRM activities undertaken by insurance companies are important factors that play a major role in affecting consumer's choice of purchasing a life insurance policy. Customer relationship management is a strategic approach that is concerned with creating new customers by developing appropriate relationship with key customers. The relationship with customers (CRM) has turned into a strategic issue for to-days companies. CRM includes all these concepts used by companies in relation to their clients including capturing, storing and analysis of information about customers. CRM is a business strategy in order to optimize revenue, enhance profit and to increase sell. So a good CRM system is the foundation of the insurance sector. (Ciprian Matis, 
2014). There is a linkage between CRM with SCM performance of an organization and increased shareholder's value (Lisa Harrington (2005). Businesses successfully linking CRM with supply chain management (SCM) achieve remarkable results. Indeed, they are twice as profitable as their competitors that do not link CRM to SCM, according to a recent Deloitte Research study.

\subsubsection{Distribution Channel}

With the development of the consumer behavior and evolution of the technology new distribution channels like Banc-assurance, direct selling, and corporate agents, on-line selling, Group Selling, brokers and cooperative societies have been developed successfully in the recent years. To maximize the reach in both rural and urban markets, many insurers are aiming to derive distribution channel advantage because each channel has unique strength (Chakraborty, 2011). Distribution channel has been helpful in overcoming the challenges and problems faced by various Indian insurers to reach the customers (Lakshmi Kutty \& Basker, 2006). It is the key for the development and the success of the insurance industry and is necessary for achieving the higher penetration and to make the supply chain management of the Insurance industry successful.

\subsubsection{Affordability}

More Innovative products and multiple channels of distribution are needed to make insurance products more affordable (Johari, 2018). Affordability is the capacity of people which is within one's financial means and the insurers should introduce the product which are seems to be affordable by the middle class people and the rural people who have the unstable and less disposable incomes. Even if awareness campaign or the multiple distribution channels became successful in convincing them that insurance is a risk mitigating technique, but unstable income restrict them to the insurance products. According to classical approach the purchase decision is influenced by the customer on the basis of his personal interest to insure against an event and financial affordability (Cristian Buzatu,2013)

\subsubsection{Accessibility}

Accessibility is the right or opportunity to use or to avail the benefit from the Insurance Services and physical reach is one of the basic determinants of accessibility (Arvind Kasturi,2018). There is still a gap with respect to awareness of the need of insurance and purchase of insurance in between rural and urban areas. On the other hand Insurers are not active enough in rural areas because of high risk and high expenses (Zhou Yanli, 2008).Due to barriers like transportation, lack of Internet and wide network connectivity, Indian insurers are not concentrating any promotional activities which impacts consumer's access to the insurance service (National Advisory committee on rural health insurance market, 2018) in rural areas.

\subsubsection{Awareness}

Now a days most disheartening fact is lack of awareness about insurance in rural and semi urban areas and in urban areas it is not up to mark also (Sunil Sacxena, 2019). Though Insurance is a common phenomenon, still the awareness of the people towards this is very low and negligible in India. If proper and adequate awareness created or generated within the people, it can create huge array of opportunity in Indian Insurance market. In India awareness about Insurance is low due to low educational status, poor functional literacy, low accent on education within the health care system,It as revealed that lack of awareness is the main reason for the less growth and development, low penetration and low density of Indian Insurance sector as comparison to other developed countries (Zainuddin Zakaria et al.,2014). Tapen Sinha, (2008) observed that high population growth rate (1.7\% of average growth rate over last 10 years) and lack of awareness are two important factors, which restricts the improvement of the insurance density of India as compared to other countries. In India The awareness of consumers for insurance products is very low because of high illiteracy rate that works against Success of SSCM of Insurance Industry. 


\subsubsection{Acceptance}

Indian Insurance market is a sellers rather than the buyers market for why there is huge untapped potential is there for Insurers. Insurance marketing involves reaching to prospective customers, understanding their wants \& needs, development of products according to their requirements \& purchasing power and selling of low ticket products to make it accepted by the people (Venketssh Ganapathi, 2019). According to Fishbein \& Ajzen (2003), the favourable perception related to individual social benefit, ease of understanding of terms of policy, price of product are likely to influence the acceptance behaviour of customers. So there is a significant link in between usage based pricing and acceptance intention of prospective customers.

\section{PROPOSED METHODOLOGY}

Interpretive Structural Modelling developed by J.N.Warfield (1974) to solve social and economic problems (D.Kumar \& D.Kumar,2015). ISM is an approved technology used for identifying the Logical relationship exits among the influential factors responsible for the solution of a complex problem (S.Tripathy \& S.Sahu,2013),Rajesh.K.Sing (2007), Sudersan Nayak \& Aishwara (2018), S.Sahu \& P. K.Ray (2013), Prashant B. Kulkarni (2018), all have used ISM either for Green Supply Chain Management,or for improving Cooperativeness of MSMEs or for performance evaluation of Indian Educational sector, and this methodology have been followed and systematically used here under the study.

As it it felt that very few research have been undertaken in the Insurance Sector using this ISM and to fill up the research gap,this study tries to establish a structural relationship among the identified factors accountable for the successful performance of SSCM of Indian insurance industry. After proceeding step by step, finally ISM was developed which was used to determine the casual and indirect relationship among the identified factors . Through this ISM technique, here the attempt has been made to establish the relationship among the 12 key influential factors and to find out short term and long term objectives of the Indian Insurance Sector.

\subsection{Steps Followed in ISM Methodology}

a) Identification of Influential factors by using the Questionnaire and Survey and examined by experts through brain storming

b) Establishment of Structural Self Interaction Matrix through comparison (Pair wise)

c) Building of reachability Matrix interaction Matrix

d) Development of Final reachability Matrix through Partition of different Levels

e) Drawn of Digraph on the basis of relationship resulted from reachability Matrix

f) Conversion of digraph into ISM through replacement of variable node with its respective statement.

(S .Tripathy et.al 2013 ; Samrat Majumdar et.al 2018)

\subsubsection{Identification of Influential Factor}

For the development of proposed ISM approach, study tried to identify various influential factors from the past literature and survey. Out of the total factors identified, again short listed in to 12 key influential factors on the basis of Expert's opinion which are responsible for successful performance of Indian Insurance Industry.The influential 12 key factors which are selected and validated are like Demography, Risk perception, Economic reforms, Product Customization, Policy terms, Rural Market, CRM, Distribution channel, Accessibility, Affordability, Awareness and Acceptance. 
Table 1. Structural Self Interaction Matrix

\begin{tabular}{|c|c|c|c|c|c|c|c|c|c|c|c|c|c|c|}
\hline $\begin{array}{l}\text { SR. } \\
\text { NO }\end{array}$ & FACTORS & NOTATI ON & PT & $\mathbf{A F F}$ & DEM & CR M & PC & $\mathrm{AC} \mathrm{C}$ & ER & APT & DC & $\mathbf{R M}$ & AWR & $\mathbf{R P}$ \\
\hline 1 & Policy Term & PT & & $\mathrm{V}$ & A & $\mathrm{V}$ & A & $\mathrm{V}$ & A & $\mathrm{V}$ & $\mathrm{V}$ & $\mathrm{X}$ & $\mathrm{V}$ & A \\
\hline 2 & Affordability & AFF & & & A & A & A & $\mathrm{x}$ & A & $\mathrm{V}$ & A & A & $\mathrm{V}$ & A \\
\hline 3 & Demography & DEM & & & & V & $\mathrm{V}$ & V & $\mathrm{x}$ & $\mathrm{V}$ & V & $\mathrm{v}$ & V & $\mathrm{x}$ \\
\hline 4 & $\begin{array}{l}\text { Customer } \\
\text { Relatioship } \\
\text { Management }\end{array}$ & CRM & & & & & A & $\mathrm{V}$ & A & $\mathrm{v}$ & $\mathrm{x}$ & A & $\mathrm{V}$ & A \\
\hline 5 & $\begin{array}{l}\text { PProduct } \\
\text { Customization }\end{array}$ & PC & & & & & & V & A & $\mathrm{V}$ & $\mathrm{V}$ & $\mathrm{V}$ & $\mathrm{V}$ & A \\
\hline 6 & Accesability & $\mathrm{ACC}$ & & & & & & & A & $\mathrm{V}$ & A & A & $\mathrm{V}$ & A \\
\hline 7 & $\begin{array}{l}\text { Economic } \\
\text { Reforms }\end{array}$ & ER & & & & & & & & $\mathrm{V}$ & V & $\mathrm{V}$ & V & $\mathrm{X}$ \\
\hline 8 & Acceptance & APT & & & & & & & & & A & A & A & A \\
\hline 9 & $\begin{array}{l}\text { Distribution } \\
\text { Channel }\end{array}$ & DC & & & & & & & & & & A & V & A \\
\hline 10 & Rural Market & $\mathrm{RM}$ & & & & & & & & & & & $\mathrm{V}$ & A \\
\hline 11 & Awarenes & AWR & & & & & & & & & & & & A \\
\hline 12 & $\begin{array}{l}\text { Risk } \\
\text { Perception }\end{array}$ & $\mathrm{RP}$ & & & & & & & & & & & & \\
\hline
\end{tabular}

\subsubsection{Establishment of Structural Self Interaction Matrix}

On behalf of the study for analyzing the key influential factors a self interaction matrix is developed with a contextual relationship with the word "leads to is chosen". To reveal the relationship between the key influential factors for the strong and effective performance of the SSCM of Indian Insurance Sector, 4 symbols have been used. These symbols used to show the contextual relationship between two factors like $\mathrm{i} \& \mathrm{j}$ (where $\mathrm{i}<\mathrm{j}$ )

Interpretations of the symbols are

$\mathrm{V}=$ Where $(\mathrm{j})$ influenced by (i)

$A=$ Where (i) influenced by $(j)$

$X=$ Where both (i) \& (j) influenced by each other.

$\mathrm{O}=$ Where no relationship exits in between(i) \& (j)

Table 1 represents the Contextual relationship of the Factors

\subsubsection{Building of Reachability Matrix}

Reachability Matrix is the next step of Structural Self Interaction Matrix and for developing this Matrix, there is necessity of substituting (1) \& (0) for the Four symbols like (V,A,X \& O) of SSIM and this SSIM will be converted into initial reachability Matrix (Table 2). The rules followed for substituting (1) \& (0) are

Where $(i, j)$ is V in IISM, then reachability matrix for $(i, j)=1 \&(j, i)=0$

Where $(i, j)$ is A in IISM, then reachability matrix for $(i, j)=0 \&(j, i)=1$

Where $(i, j)$ is $X$ in IISM, then reachability matrix for $(i, j)=1 \&(j, i)=0$

Where $(i, j)$ is $O$ in IISM, then reachability matrix for $(i, j)=0 \&(j, i)=0$ also.

So in this step following this logic the initial reachability Matrix is developed

Where $(i, j)$ is $O$ in IISM, then reachability matrix for $(i, j)=0 \&(j, i)=0$ also.

So in this step following this logic the initial reachability Matrix is developed 
Table 2. Reachability Matrix

\begin{tabular}{|l|l|l|l|l|l|l|l|l|l|l|l|l|l|}
\hline Factors & PT & AFF & DEM & CRM & PC & AC C & ER & APT & DC & RM & AWR & RP & $\begin{array}{l}\text { Driving } \\
\text { powers }\end{array}$ \\
\hline PT & 1 & 1 & 0 & 1 & 0 & 1 & 0 & 1 & 1 & 1 & 1 & 0 & 8 \\
\hline AFF & 0 & 1 & 0 & 0 & 0 & 1 & 0 & 1 & 0 & 0 & 1 & 0 & 4 \\
\hline DEM & 1 & 1 & 1 & 1 & 1 & 1 & 1 & 1 & 1 & 1 & 1 & 1 & 12 \\
\hline CRM & 0 & 1 & 0 & 1 & 0 & 1 & 0 & 1 & 1 & 0 & 1 & 0 & 6 \\
\hline PC & 1 & 1 & 0 & 1 & 1 & 1 & 0 & 1 & 1 & 1 & 1 & 0 & 9 \\
\hline ACC & 0 & 1 & 0 & 0 & 0 & 1 & 0 & 1 & 0 & 0 & 1 & 0 & 4 \\
\hline ER & 1 & 1 & 1 & 1 & 1 & 1 & 1 & 1 & 1 & 1 & 1 & 1 & 12 \\
\hline APT & 0 & 0 & 0 & 0 & 0 & 0 & 0 & 1 & 0 & 0 & 0 & 0 & 1 \\
\hline DC & 0 & 1 & 0 & 1 & 0 & 1 & 0 & 1 & 1 & 0 & 1 & 0 & 6 \\
\hline RM & 1 & 1 & 0 & 1 & 0 & 1 & 0 & 1 & 1 & 1 & 1 & 0 & 8 \\
\hline AWR & 0 & 0 & 0 & 0 & 0 & 0 & 0 & 1 & 0 & 0 & 1 & 0 & 2 \\
\hline RP & 1 & 1 & 1 & 1 & 1 & 1 & 1 & 1 & 1 & 1 & 1 & 1 & 12 \\
\hline Dependence & 6 & 10 & 3 & 8 & 4 & 10 & 3 & 12 & 8 & 6 & 11 & 3 & \\
\hline
\end{tabular}

\subsubsection{Development of Final reachability Matrix Through Level Partition}

The level of Partitioning is generally done with the aim to classify the factors into different levels on the basis of two sets associated with each other like reachability set and Antecedent Set and these two sets are carried forward from the final reachability Matrix. Final Reachability Matrix developed by taking into account all the variables with their binary figures denoted by Reachability set and Antecedent set.The variables for which both the reachability and intersection set are same are treated as top level factor. After identification of top level factor, immediately it is discarded from other factors and the process will continue till getting the levels for all other factors. This process of iteration will continue till the attainment of levels for each variables. So partition levels help to dictate the ranking or hierarchy of all variables. The identified levels will help to built the diagraph and final model of ISM for concluding the study. In the study the identification of all the levels are shown in the Tables 3 and 4.

Similarly seven iterations have been done to determine the seven levels of ISM.

\subsubsection{Classification of Factors and Draw-up of Digraph}

Factors which are identified as influential for the effective performance of SSCM of Indian insurance industry are classified into 4 categories such as Autonomous, Dependant, Linkage and Independent factors shown in Figure 2 and Table 1. The SSCM of Indian insurance industry (III) which is clustered into four broad categories like Autonomous (not having connection with other factors, disconnected from the system, weak driving power and strong by itself), Dependent (having features like less driving power, strong dependencies and connected with the system). Linkage (combination of strong dependencies on other factors, strong steering and pushing power) and Independent Factors (strong driving power but less dependencies on other factors). All these factors are shown in the below Graph. Figure 2, Driver Dependence Matrix, depicts the valuable inputs about the driving and inter dependencies among the key influential factors for the success of Insurance industry.On the basis of driving power and dependence of each variable the digraph (bubble diagram) has been constructed which is depicted in Figure 2. 
Table 3. Iteration 1

\begin{tabular}{|c|c|c|c|c|}
\hline INT:1 Factor & Reachability- Set & Antecedent -Set & Intersection -Set & Level \\
\hline $\mathrm{PT}(1)$ & $1,2,4,6,8,9,10,11$ & $1,3,5,7,10,12$ & 1,10 & \\
\hline $\operatorname{AFF}(2)$ & $2,6,8,11$ & $1,2,3,4,5,6,7,9,10$ & 2,6 & \\
\hline $\operatorname{DEM}(3)$ & $1,2,3,4,5,6,7,8,9,10,11,12$ & $3,7,12$ & $3,7,12$ & \\
\hline CRM(4) & $2,4,6,8,9,11$ & $1,3,4,5,7,9,10,12$ & 4,9 & \\
\hline $\mathrm{PC}(5)$ & $1,2,3,4,5,6,8,9,10,11$ & $3,5,7,12$ & 5 & \\
\hline $\operatorname{ACC}(6)$ & $2,6,8,11$ & $1,2,3,4,5,6,7,9,10,12$ & 2,6 & \\
\hline $\operatorname{ER}(7)$ & $1,2,3,4,5,6,7,8,9,10,11,12$ & $3,7,12$ & $3,7,12$ & \\
\hline APT(8) & 8 & $1,2,3,4,5,6,7,8,9,10,11,12$ & 8 & 1 \\
\hline $\mathrm{DC}(9)$ & $2,4,6,8,9,11$ & $1,3,5,7,9,10,12$ & 4,9 & \\
\hline $\mathrm{RM}(10)$ & $1,2,4,6,8,9,10,11$ & $1,3,5,7,10,12$ & 1,10 & \\
\hline $\operatorname{AWR}(11)$ & 8,11 & $1,2,3,4,5,6,7,9,10,11,12$ & 11 & \\
\hline $\mathrm{RP}(12)$ & $1,2,3,4,5,6,7,8,9,10,11,12$ & $3,7,12$ & $3,7,12$ & \\
\hline
\end{tabular}

\subsubsection{Transformation of Digraph into ISM Model}

After the construction of the diagraph, it will be converted into ISM which is the final step by replacing the element nodes with narration (Figure 3). This model is constructed from the results of the reachability matrix in Figure 3, which shows the driving power and dependence of all the elements. At the end, generally ISM model is reviewed to check the inconsistency.

Table 4. Level Partitions of Influencing Factors after 7 Iterations

\begin{tabular}{|l|l|l|}
\hline SI. No & Influencing actors of SSCM of Indian Insurance Industry & Levels \\
\hline 1 & Policy Terms (PT) & V \\
\hline 2 & Affordability (AFF) & III \\
\hline 3 & Demography (DEM) & VII \\
\hline 4 & Customer Relationship (CRM) & IV \\
\hline 5 & Product Customization (PC) & VI \\
\hline 6 & Accessibility (ACC) & III \\
\hline 7 & Economy Reforms (ER) & VII \\
\hline 8 & Acceptance (APT) & I \\
\hline 9 & Distribution Channel (DC) & IV \\
\hline 10 & Rural Market (RM) & V \\
\hline 11 & Awareness (AWR) & II \\
\hline 12 & Risk Perception (RP) & VII \\
\hline
\end{tabular}




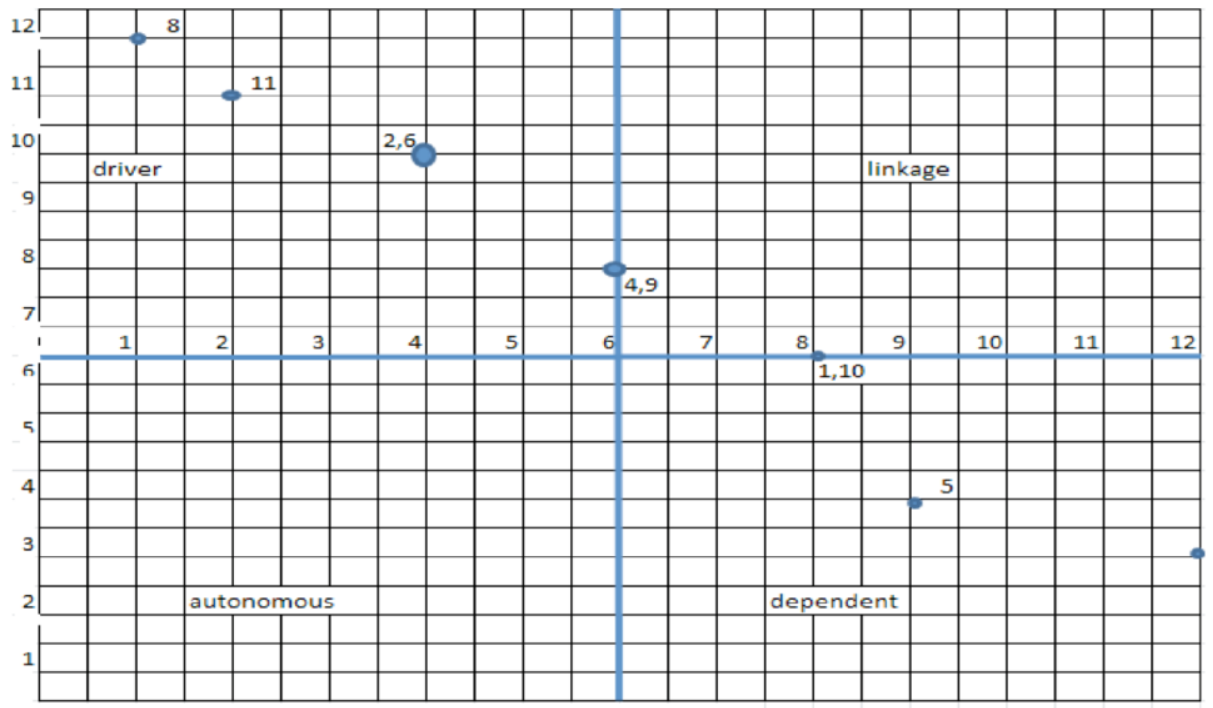

\section{RESULTS AND DISCUSSION}

During the study ISM depicts how the Growth drivers, Linkage, Autonomous and Dependent factors are distributed in various levels and how one driver influence the other factors through in-between links (Rameshwar,Dubeya,2017)

The study provides some more important points which attracts the attention and discussed

1) In this study it is discovered that there is no autonomous factor which are generally weak driver and weak dependency. This finding states that out of 12 key important factors, no factor found that can influence the other factors of the system for the successful performance of the SSCM of the Indian Insurance Companies. These variables only have few links which are not strong by itself.

2) Four factors such as acceptance, awareness, affordability and accessibility are falling under which are weak driver but strongly dependent on other variables. These variables are shown in the top of ISM model (Figure 3) and focus on these factors are long term objectives of SSCM of Indian Insurance Industry.

3) After Autonomous and Dependent next factors identified is Linkage and factors coming under this category are most important factors for the Organization. These factors possess more driving power and they are strong dependent on other factors. These are unstable in nature and any change resulting to them will affect to other factors and in turn will affect the whole system of the Organization. It is inferred from the study that the factors like CRM, Distribution Channel. Policy terms and Rural Market are more unstable. But two only out of 4 like CRM and Distribution Channel are not placed exactly in Linkage zone but nearer to Driving and other two factors like 


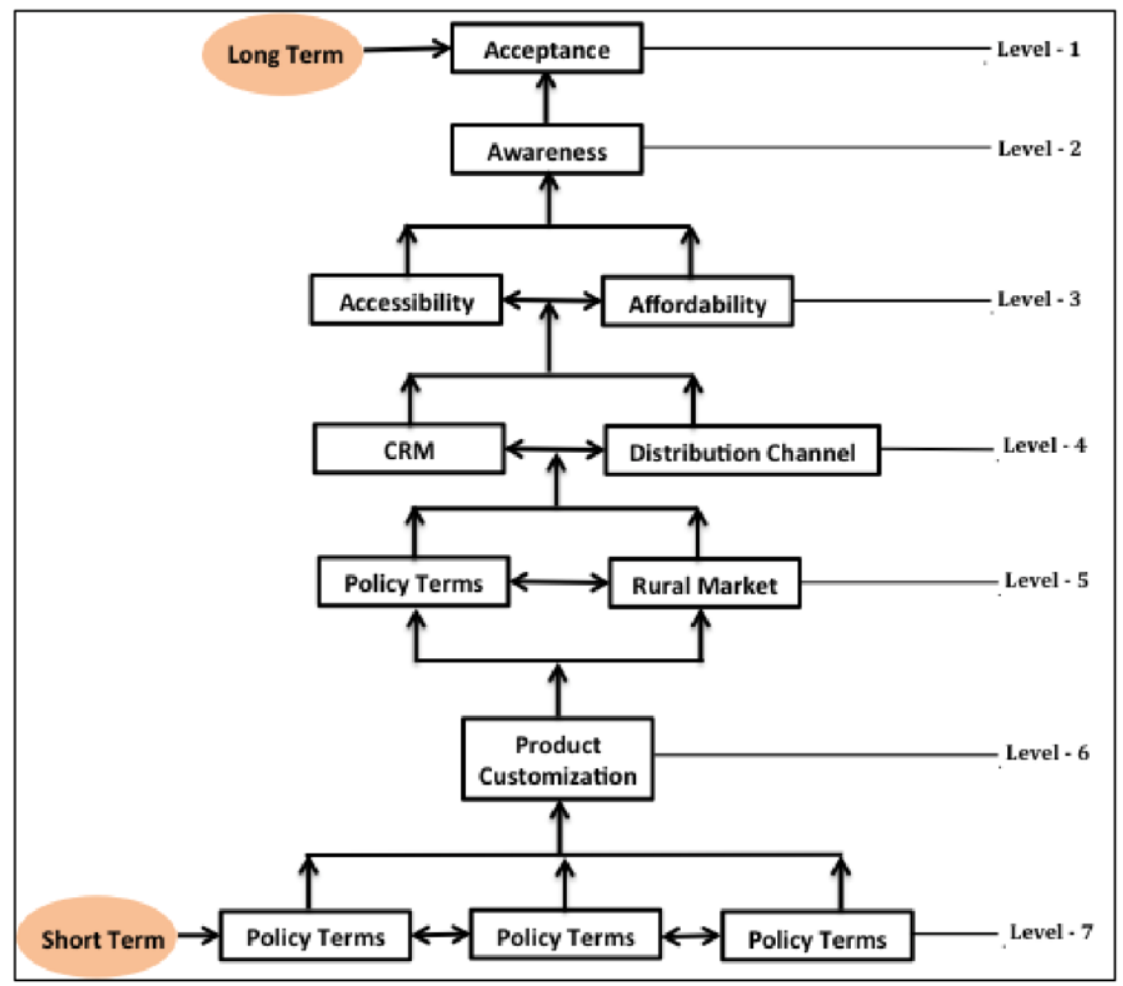

Policy Terms and Rural Market are nearer to Dependent. Therefore more focus is needed to for all these four factors.

4) The remaining four factors designated as Drivers which are Product Customization, Demography. Economic Reforms and Risk Perception. These factors are placed at the bottom of the model and recognized as short term objectives of the Industry. These four factors have more driving power \& Strategic orientation. The highly appreciated performance of Insurance industry can be improved by improving these factors continuously. So finally it can be concluded that Insurers should focus more attention to the above factors to achieve the long term objectives such as awareness \& acceptance to make SSCM in most efficient way within a short span of time.

\section{CONCLUSION AND RESEARCH IMPLICATION}

Though the Indian Insurers, IRDA \& Policy Makers are conscious about the key influential enablers of the Insurance industry, still a well defined approach is necessary for pointing out them into different categories to know the driving forces for the success of the industry. The systematic approach applied here is the ISM, which spell out the root cause factors which are really determinant and demand more centre of attention for the result oriented performance of SSCM of Indian insurance industry.The findings of the study will enable the Indian and foreign insurers to clearly understand the consumer's 
attitude and perception along with their buying behavior while purchasing the insurance products. Through the help of the study the insurers will be equipped to motivate the prospective customers to purchase insurance products as per their need. The present study will help the researchers and insurance policy framers in understanding the factors and their inter-dependency that influence the service supply chain management of insurance industry. The identified key influential factors structured in this study are essential for facilitating for the success of the Insurance and other industry. It also helps the Management to take the appropriate action in order to enhance up graded performance of their companies. Therefore the Indian insurers should pay attention on these key important factors and their interactive relationship to measure the performance of SSCM of Indian insurance industry. The proposed ISM Model have taken into consideration only 12 influential factors, but more number of factors may be taken into consideration in future research, which will provide a clear understanding by establishing the inter-relationship among factors and identifying the main driving force for the successful performance of SSCM of Indian insurance industry. This paper concludes with some limitations and paves the way for further research to a greater extent. 


\section{REFERENCES}

Aich, S., Chakraborty, A., \& Lee, G. M. (2016). Information technology is an enabling factor affecting supply chain performance in Indian SMEs. Journal of Modelling in Management, 4(2), 42-45.

Ali, D., Kannanb, D., \& Mathiyazhagan, K. (2014). Analysis of enablers for implementation of sustainable supply chain management - A textile case. Journal of Cleaner Production, 83, 391-403. doi:10.1016/j. jclepro.2014.06.081

Anil, E.N., \& Sridharan, R. (2019). Sustainable Supply Chain Management: A Literature Review and Implications for Future Research. International Journal of System Dynamics Applications, 8(3), 57-71.

Arash, S. (2010). SSCM: Service Supply Chain Management. International Journal of Logistics Systems and Management, 6(1), 029721. doi:10.1504/ IJLSM

Ashfaque, A. (2013). Rural Marketing for Selling Products \&Services: Issues \& Challenges. Journal of Business Management \& Social Sciences Research, 2(1), 55-60.

Baltacioglu, T., Ada, E., Kaplan, O., \& Kaplan, Y. C. (2007). A New Framework for Service Supply Chains. Service Industries Journal, 27(2), 105-124. doi:10.1080/02642060601122629

Bentalha, B., \& Hmioui, A. (2019). The digitalization of the supply chain management of service companies: a prospective approach. SCA '19: Proceedings of the 4th International Conference on Smart City Applications, 1-8. doi:10.1145/3368756.3369005

Bhushan, S. (2017). System Dynamics Base-Model of Humanitarian Supply Chain in Disaster Prone EcoCommunities of India: A Discussion on Simulation and Scenario Results. International Journal of System Dynamics Applications, 6(3), 20-37. doi:10.4018/IJSDA.2017070102

Brown, V. J. (2014). Risk Perception: It's Personal Environmental Health Perspectives. Environmental Health Perspectives, 122(10), 276-279. doi:10.1289/ehp.122-A276 PMID:25272337

Buzatua, C. (2013). Post Crisis Economy: Challenges and Opportunities, The Influence of Behavioral Factors on Insurance Decision a Romanian Approach. Procedia Economics and Finance, 6, 31-40. doi:10.1016/S22125671(13)00110-X

Catia, D., \& Paulo, S.A. (2005). Do Supply Chain Management Practices Influence Firm Performance?: A MetaAnalytical Approach. International Journal of Information Systems and Supply Chain Management, 13(3), 22.

Confederation of Indian Industry. (2018). Competing in a new age of insurance: How India is adopting emerging technology. https://www.pwc.in/assets/pdfs/consulting/ financial- services/ competing- ina-new -age-of - insurance

Cruz, Y., \& Cantillo. (2018). A System Dynamics Approach to Humanitarian Logistics and the Transportation of Relief Supplies. International Journal of System Dynamics Applications, 3(3), 96-126.

Das, K., \& Dellana, S. A. (2013). A Quality and Partnering-Based Model for Improving Supply Chain Performance. International Journal of Strategic Decision Sciences, 4(3), 31. doi:10.4018/jsds.2013070101

Dubey, R., Gunasekaran, A., Papadopoulos, T., \& Childe, S. (2016). Sustainable Supply Chain Management: Framework and Further Research Directions. Journal of Cleaner Production. Advance online publication. doi:10.1016/j.jclepro.2016.03.117

Farokhian. S., \& Sadeghi, T. (2011). The Determination of the Critical Success Factors (CSFs) in Insurance Services in Iran. Asian Journal of Business Management Studies, 2(1), 4-6.

Fishbein \& Ajzen. (2005). The Influence of Attitudes on Behavior. https://www.researchgate.net/ publication/264000974

Ganapathi, V. (2019). Insurance \& Rural Development. Journal of Insurance Institute of India, 7(4), 3-10. 
Gunasekarana, A., Patel, C., Ronald, E., \& Gaugheyc, M. (2004). A framework for supply chain performance measurement. International Journal of Production, 87(3), 333-347. doi:10.1016/j.ijpe.2003.08.003

Habib, M. (2011). Supply Chain Management (SCM): Theory and Evolution. .10.5772/24573

Hakaki, A., Shafiei, M., \& Nikabadi. (2018). Dynamic Model of Effective Factors on Open Innovation in Manufacturing Small and Medium Sized Companies. International Journal of System Dynamics Applications, $7(1), 1-26$.

Harrinton, L. (2005). When Customer is King. inboundlogistics.com/cms.Article/WhentheCustomerisKing

Hendricks \& Singhal. (2005). An empirical Analysis of the effect of supply chain Management on long run stock price performance and equity risk of the Firm. Production and Operations Management, 14(1), 35-52.

Icek, A., \& Martin, F. (2005). The Influence of Attitudes on Behavior. The handbook of attitudes, 173, $173-221$. https://www.researchgate.net/publication/264000974

Iqbal, C. M. (2019). Supply Chain Risk Assessment in the Ornamental Fish Supply Chain. International Journal of System Dynamics Applications, 8(2), 15. doi:10.4018/IJSDA.2019040103

Karadayi, U., Serdar, A., S. (2014). A Framework for Service Supply Chain Management Literature. CIE44 \& IMSS'14 Proceedings, 572-580.

Kasturi, A. (2018). Challenges to Health care in India - The Five A's. Indian Journal of Community Medicine, 43(3), 141-143. PMID:30294075

Khan, H., \& Vazirani, K. (2017). Life Insurance Industry in India - Current Scenario. International Journal of Engineering and Management Science, 8(1), 65-71.

Krohn, A., Gupta, A., \& Chadha, A. (2017). Cloud computing in optimizing supply chain management of automotive component industry. Proceedings of the 1st International Conference on Internet of Things and Machine Learning, (71), 1-3. doi:10.1145/3109761.3109807

Kulkerni, P.B., Ravi, K., \& Patil, S.B. (2018). Interpretive Structural Modeling for implementation of Green Supply Chain Management in Construction Sector of Maharasta. International Journal of Engineering \& Technology, 5(5).

Kumar, D., \& Kumar, D. (2015). Modelling Hospital Inventory Management using Interpretive Structural Modelling Approach. Int. Journal Logistics Systems \& Management, 21(3), 319-334. doi:10.1504/ IJLSM.2015.069730

Lia, S., Nathanb, Ragunathanb, T.S., \& Subba Raob, S. (2004). The impact of supply chain management practices on competitive advantage and organizational performance. International Journal of Management Science. doi: 2004.08.00210.1016/j.omega

Luthra, S., \& Haleem, A. (2015). Hurdles in implementing Sustainable Supply Chain Management: An analysis of Indian automobile sector. XVII Annual International Conference of the Society of Operating Management, $189,175-183$.

Majumdar, S., \& Tripathy, S. (2018). Performance Evaluation of Indian Education Sector using Interpretive Structural Modelling. IOP Conf. Series: Materials Science and Engineering, 390. doi:10.1088/1757899X/390/1/012014

Mati, C., \& Liviu, I. (2014). Emerging Market Queries in Finance and Business Customer relationship management in the insurance industry. Procedia Economics and Finance, 4(5), 22-34.

Ming, K., Lima, M., Lang, T., Sengb, K., Hua, T., \& Dat, B. (2017). Knowledge management in sustainable supply chain management: Improving performance through an interpretive structural modelling approach. Journal of Cleaner Production, 162(20), 806-816.

Mohmood, M., \& Mengeke, Y. (2017). Analysis of Success Factors to Implement Sustainable Supply Chain Management Using Interpretive Structural Modeling Technique: A Real Case Perspective. Mathematical Problems in Engineering, 1-15. doi:10.1155/2017/7274565 
Mohseni, M., Beheshti, S., \& Siadat, S. H. (2018). Sustainable Supply Chain Management Practices in Petrochemical Industry using Interpretive Structural Modeling. International Journal of System Dynamics Applications, 12(1), 29.

Montserrat, G., Jens, N., Thomas, S., \& Perez-Marin, A. (2012). Time-Varying Effects in the Analysis of Customer Loyalty: A Case Study in Insurance. Expert Systems with Applications, 39(3), 3551-3558. doi:10.1016/j. eswa.2011.09.045

Narayan, J. (2009). Role of CRM in Life Insurance Business. IRDA Journal, 4(57), 7-14.

National Advisory Committee. (2018). National Advisory Committee Insights on Rural Health Insurance Market Challenges. Rural Health Information Hub.

Onafalujo, A. K., Abass, O. A., \& Dansu, S. F. (2011). Effects of risk perception on the demand for insurance: Implications on Nigerian road users. Journal of Emerging Trends in Economics and Management Science, 2(4), 285-290.

Reddy, Y. V., Swetha, D., \& Poornima, B. G. (2015). An analysis of factors influencing consumer's choice of life insurance policies in North Goa. Aloysius Journal of Management and Research, 3(3), 57-68.

Saliha, K. (2014). A Framework for Service Supply Chain Management Literature. Conference Paper. Joint International Symposium.

Saxena, S. (2019). Insurance and Rural Development; Challenges and Opportunity. The Journal of Insurance Institute of India, 7(1), 70-74.

Schramm, C. (2008). Innovation Measurement: Tracking the State of Innovation in the American Economy. SSRN Electronic Journal. 10.2139/ssrn.1090630

Shahin, A. (2010). SSCM: Service Supply Chain Management. International Journal of Logistics Systems and Management, 6(1), 60. Advance online publication. doi:10.1504/IJLSM.2010.029721

Sharma, R., \& Pratima, M. (2014). Integration of Six Sigma and ISM to improve Supply Chain Coordination - A conceptual framework. International Journal of Production Management and Engineering, 3(1), 75-85.

Sharma, S. K., Bhat, A., Kumar, V., \& Agarwal, A. (2017). Path Analysis Model for Supply Chain Risk Management. International Journal of Information Systems and Supply Chain Management, 10(2), 21-41. doi:10.4018/IJISSCM.2017040102

Sing, R. K. (2007). Interpretive Structural Modelling of factors for improving competitiveness of SMEs. International Journal of Productivity and Quality Management.

Sing, R. K. (2007). Interpretive Structural Modelling of factors for improving competitiveness of SMEs. International Journal of Productivity and Quality Management.

Singhal, D., Tripathy, S., Jena, S. K., Nayak, K. K., \& Dash, A. (2018). Interpretive structural modelling (ISM) of obstacles hindering the manufacturing practices in India. Procedia Manufacturing, 20, 452-457. doi:10.1016/j. promfg.2018.02.066

SinhaT. (2005).The Indian Insurance Industry: Challenges and Prospects. Electronic Journal. doi: 10.2139/ ssrn.79216

Somabutr, S., Pandian, S., \& Roh, S. (2020). The Configuration Structure of Service Supply Chain Management. Proceedings of the 2020. 3rd International Conference on Computers in Management and Business, 301-305. doi: $10.1145 / 3383845.3383892$

Soni, S., \& Chorasia, B. K. (2017). Policy Planning in Higher Technical Education: A System Dynamic Approach. International Journal of System Dynamics Applications, 6(3), 87-110. doi:10.4018/IJSDA.2017070105

Sridevi, P. (2012). A Study of Buying Behaviour of Consumers towards Life Insurance Policies in Perambalur District. International Journal of Research in Management, Economics and Commerce, 2(5), 84-108.

Tee Kien Hui, L. A. C., \& Santhanarajan, M. E. (2019). Proceedings of 2nd International Conference on E-Business. Information Management and Computer Science, (16), 1-5. 
Tripathy, S., Sahu, S., \& Ray, P. K. (2013). Interpretive structural modelling for critical success factors of R\&D performance in Indian manufacturing firms. Journal of Modelling in Management, 8(2), 212-240. doi:10.1108/ JM2-11-2011-0061

Vinod, R., Kevin, K., \& Hendricks, B. (2009). An Empirical Analysis of the Effect of Supply Chain Disruptions on Long Run Stock Price Performance and Equity Risk of the Firm. Production and Operation Management, 14(1). doi: .1937-5956.2005.tb00008<ALIGNMENT.qj></ALIGNMENT >10.1111/j

Watson, R. H. (1978). Interpretive structural modeling-A useful tool for technology assessment. Technological Forecasting and Social Change, 11(2), 165-185. doi:10.1016/0040-1625(78)90028-8

Yang, M., Zeng, J., \& Zhou, Z. (2014). Analysis of Success factors to implement sustainable Supply Chain Management Using ISM Technique: A real case Prospective. Mathematical Problems in Engineering, 14. $10.1155 / 2017 / 7274565$

Yanli, Z. (2008). A Comparative Study of International Insurance Markets. The Geneva Papers on Risk and Insurance. Issues and Practice, 34(2), 585-587.

Yusuf, Y. Y., Gunasekaran, A., Musa, A., Dauda, M., \& Cang, S. (2014). A relational study of supply chain agility, competitiveness and business performance in the oil and gas industry. International Journal of Production Economics, 147, 531-543. doi:10.1016/j.ijpe.2012.10.009

Zailani \& Kumar. (2011). Barriers to Product Return Management in Automotive Manufacturing Firms in Malaysia. Journal of Cleaner Production. DOI: .jclepro.2016.08.16010.1016/j

Zakaria, Z., Azmib, N. M., Hassanc, N. F. H. N., Sallehd, W. A., Tajuddine, M. T. H. M., Sallem, N. R. M., \& Noorg, J. M. M. (2016). The Intention to Purchase Life Insurance: A Case Study of Staff in Public Universities. Procedia Economics and Finance, 37, 358-365. doi:10.1016/S2212-5671(16)30137-X

Zhang \& Chen. (2015). Quality Control in Food Supply Chain Management: An Analytical Model and Case Study of the Adulterated Milk Incident in China. International Journal of Production Economics, 152, 188-199.

Puspalata Mahapatra (PhD) now working as an Assistant Professor (II) in KIIT DU, Odisha. She has received her M.com, MBA and Ph.D degree from Utkal University, Vanibihar, Bhubaneswar, Odisha. She has 14 years of teaching experience in different B.Schools of Odisha. She has more than 15 publications in different journals and more than 20 papers presented in both national and international conferences. Her area of interest is Financial Accounting, Financial Management and Financial Service, Corporate Law, Insurance and Banking Services.

Sushanta Tripathy $(P h D)$ is presently working as a Professor at the School of Mechanical Engineering in KIIT University, Bhubaneswar, Odisha, India. He completed his PhD from the Department of Industrial Engineering and Management, Indian Institute of Technology, Kharagpur. His major areas of interest include production operations management, multivariate analysis, service operations management, supply chain management and productivity management. He is a Fellow in the Institution of Engineers, India.

Suryakanta Panda $(P h D)$ is currently working as reader in commerce in Kunja Bihari College Barang, Bhubaneswar, Odisha. Dr. Panda is having teaching experience of more than 30 years both in Post-Graduate and Under Graduate level in the field of Commerce and Management. He has represented as Chairman in the advisory board of reputed $B$ schools and technical colleges in the state over a period of 22 years. He has organised and attended many national and international seminars. He has also presented around 15 research papers in different conferences and published 5 papers in different journals. 